\title{
The Impact of Quality Air in The Engine Room on the Crew
}

\author{
M.Panaitescu \& F.V. Panaitescu \\ Maritime University, Constanta, Romania \\ M.V. Dumitrescu \& V.N. Panaitescu \\ Politehnica University, Bucharest, Romania
}

\begin{abstract}
A The novelty of this study consists in the fact that, at the same time as the monitoring and acquisition of data of the air quality (from inside and outside), a monitoring and acquisition of data of the realtime biometric measurements of subjects exposed directly to the needle will be made. Medium by means of a bracelet attached to the subject's arm. This bracelet is designed to perform biometric measurements without creating discomfort to the subjects analyzed in the activities in which they are involved. This measurement is carried out with 9 different sensors for: pulse, oxygen in the blood, air flow (breathing), body temperature, electrocardiogram, galvanic skin response, blood pressure, the patient's position/movement, and the status of muscle (electromyography sensor). The data thus obtained will be focused on a PC and subsequently analyzed. The results of monitoring the health parameters of the subjects analyzed find application in the maritime field, to ships, especially in the engine room, where the air suffers quality transformations. The crew's return to the workplace may decrease due to the degradation of the air quality in the premises.
\end{abstract}

\section{INTRODUCTION}

\subsection{The purpose of study}

The purpose of the research, in the first part, is to test and evaluate the new generation of microsensors in the field of air monitoring and health monitoring in the working conditions on board the ship. The reduced costs, the accuracy of the increased reading of data and the ease in communication make the new generation of sensors very easy to integrate into and to the systems of monitoring, alarm and transmission data already integrated into the construction of ships. The quantity, quality, spatial and speed of the optinated data can successfully replace the old cumbersome procedures for analysing the air quality and monitoring the biometric values of the personnel serving the ship.
A set of instruments, consisting of two separate units, a fixed one to continuously observe the air parameters in the working areas on the ships and the other furniture, attached to the hand (arm), to monitor the 8 biometric values of the worker serving the ship and working In the monitored area were developed to obtain a better picture of the working conditions on board ships and a real-time monitoring of the health status (and stress to effort) of the workers on the ship.

The data thus collected can be corroborated for the performance of safety strategies and the creation of low-risk working conditions.

Two identical sets were built and mounted in a ship. (along with a wide range of sophisticated monitoring and calibration tools.) The instruments were exposed to common sources of pollution from the inside, in a semi-controlled experiment and during the normal exploitation of the ship. 
The results indicate that each sensor does not require individual calibration.

The readings made by them fall within the error margins specified by the manufacturer.

Thus the sensor responses were very consistent and correlated with much more costly tools.

The combination of the data provided by the sensors is still being analyzed.

\subsection{Necessity and timeliness of the study}

The technology for monitoring the quality of classical air has reached its technological and cost limits.

As spatial monitoring improves, pollution sources, dispersion patterns and health effects can be better addressed, while reducing dependency on predictive models. Thus, the need to complement and supplement the conventional air quality monitoring networks, with alternative, punctual, local approaches capable of capturing fine changes in these levels of variability and from Microsystems of Environment.

Passive sampling assemblies, mobile monitoring and emerging sensory technologies are all approaches that have been used to address spatial coverage.

The sensor market has flourished in recent years, resulting in air quality, economic, low-power, miniature, autonomous (and usually easy to connect to the Internet) monitoring units. Although these units were less precise when marketed for the first time, subsequent generations demonstrate improved reliability and rigour. Equipment made with these tools includes real-time data collection, locationspecific. The results can be used as an educational instrument, promoting, air quality awareness, while helping to change the pattern of time activity to reduce harmful exposure to atmospheric contaminants. This revolution in sensors and related applications can provide sustainable solutions for applications in monitoring, education, community monitoring, the supplementation of ambient air monitoring networks or even conformity assessment.

Equipment made with these tools, attached to human subjects, allows the acquisition of data and the creation of a new image of the conformity of working conditions and anticipation of unwanted events.

It is a matter of time before shipping ships will have integrated systems to monitor air quality values as well as biometric staff values.

\section{MATERIALS AND METHODS}

\subsection{Requirements}

Our agreed requirements for the toolkit were:

- Low unit cost

- Small form factor

- Easy use (in case of bracelets)

- Use of the new generation of sensors

- ompatibility with ship's supply and communication systems

- Compatibility with shore monitoring programs
- Issuing alarms

- Minimal electrical interference with ship's systems

- Low energy consumption

- Operating period without intervention for 5 years

- The possibility of easy upgrading to new generation of sensors (still in development).

For prototyping:

- the design of hardware and software "Open source " has been addressed in order to benefit from the expertise and knowledge of the global development Community and, therefore, to minimize replication ease and reduce the time of development of equipment.

- the use of the new generation of low cost sensors and the very small form factor, developed at the urging of the European Union and UNICEF and made by the great manufacturers specializing in the production of electronic sensors.

These new generation sensors do not transmit to the microprocessor an electrical value which then is to be converted into the unit of measurement in the international system of the measured elements and then require a calibration of these readings. The $\mathrm{I}^{2} \mathrm{C}$ transmission sensors directly transmit the value of the element measured in units of measurement in the international system to the processor.

\subsection{Description of equipments}

Two equipments are used: a fixed one and another mobile. The main microcontroller used in both equipments is Atmega328 in SMD technology (for miniatures)(Figure 1).

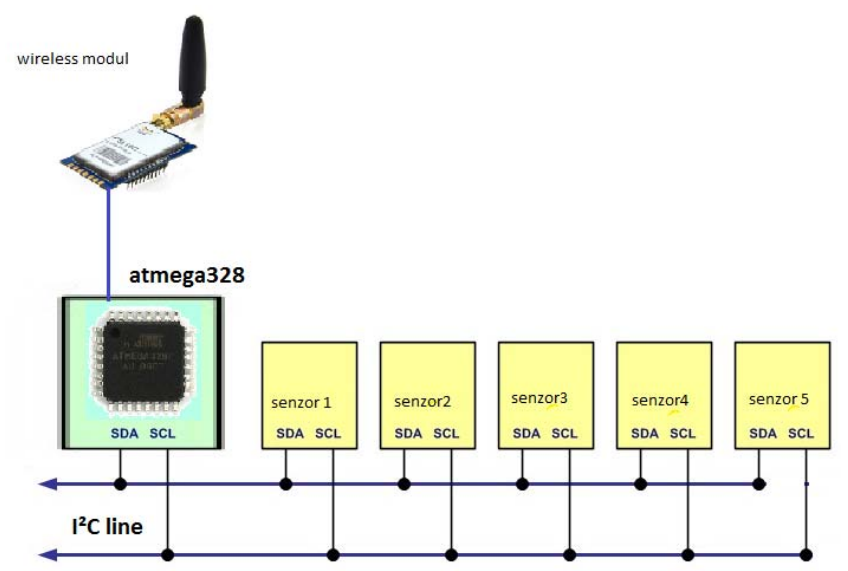

Figure 1. Block diagram of acquisition and data transmission from sensors (identical for the fixed and mobile unit).

Main sensors used:

For the fixed unit:

- Optical dust sensor: GP2Y1010AU0F Sharp

- Sensor for NO3, CO, NH3: MiCS-6814 SGX Sensortech

- Temperature and humidity pressure sensor: BME $680 \mathrm{BOSCH}$.

For the mobile unit:

- Oximeter pulse\& integrated heart rate sensor MAX30100 Maxim Integrated

- Sensor for NO3, CO, NH3: MiCS-6814 SGX Sensortech 
- Temperature and humidity pressure sensor: BME $680 \mathrm{BOSCH}$

- Motion sensor (Accelerometer): MPU-6000 InvenSense

- Body temperature sensor:

- Sweat sensor.

Both fixed and mobile units are coupled through the ship's wireless system with a terminal monitor and synchronized with the ship's time. This terminal is for storing data (which can also be done by the terrestrial terminal in real time) and for issuing warnings to the service officer (Figure 2).

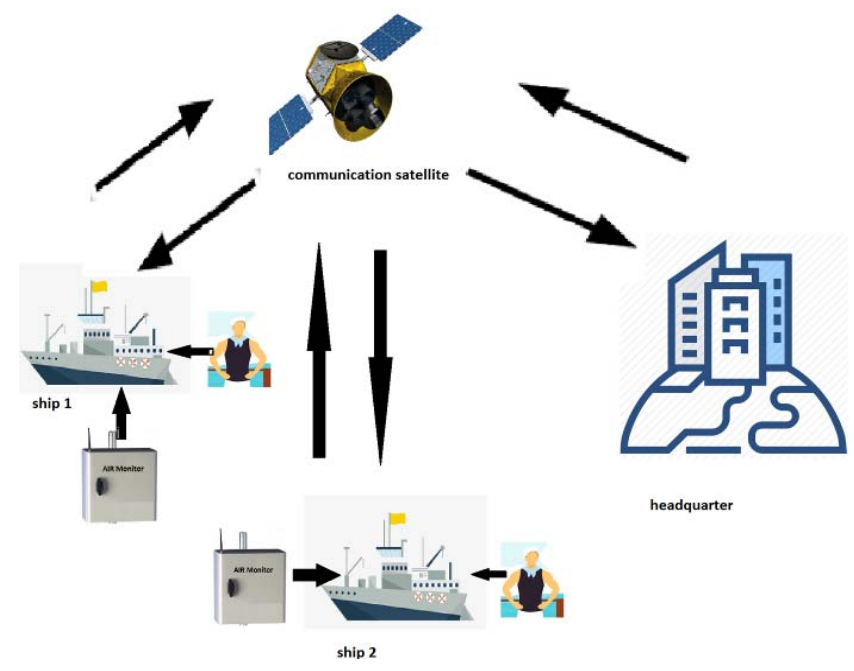

Figure 2. System Data Flow

The main microcontroller used in both the fixed and mobile devices is Atmega328 in SMD technology.

The key elements of this system designed were that all the sensors chosen to be compatible with the I 2 C protocol for easier interconnection with the processor, but also in order to be able to achieve without difficulty the upgrading of the equipment.

- Fixed Unit (Figure 3):

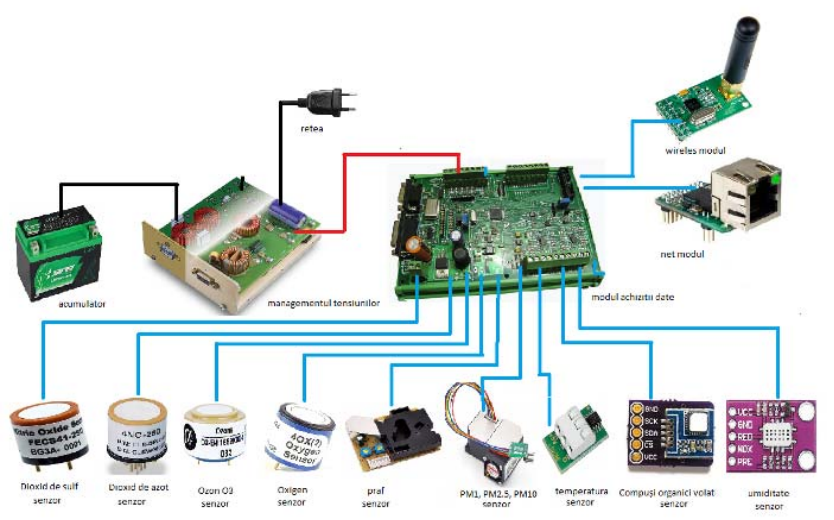

Figure 3. Fixed unit block Schema

- Electronic Bracelet (mobile unit)

The electronic bracelet is designed to perform noninvasive biometric measurements without disturbing the subjects in the activities in which they are involved (Figure 4). This measurement is achieved with 8 different sensors for: pulse, oxygen in the blood (SPO2), body temperature, electrocardiogram (ECG), Galvanic skin response (GSR-sweating), blood pressure (aneroid), position/movement of (accelerometer) and the muscle/electromyography (EMG) sensor (Figure 5). The data thus obtained will be centralised on a PC and subsequently analyzed with synchronized time-based comparison. This can see the direct effect of air quality on subjects.

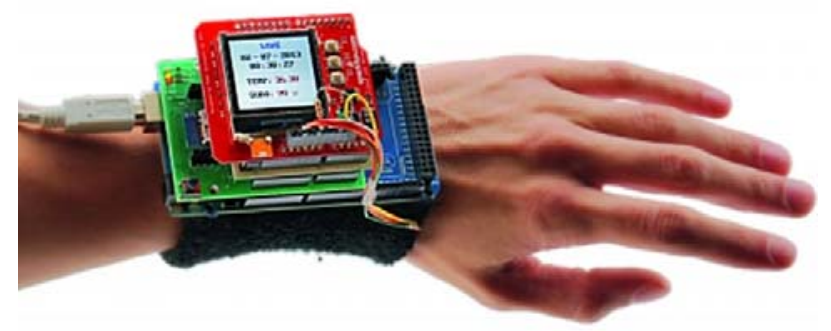

Figure 4. The electronic bracelet (mobile unit)

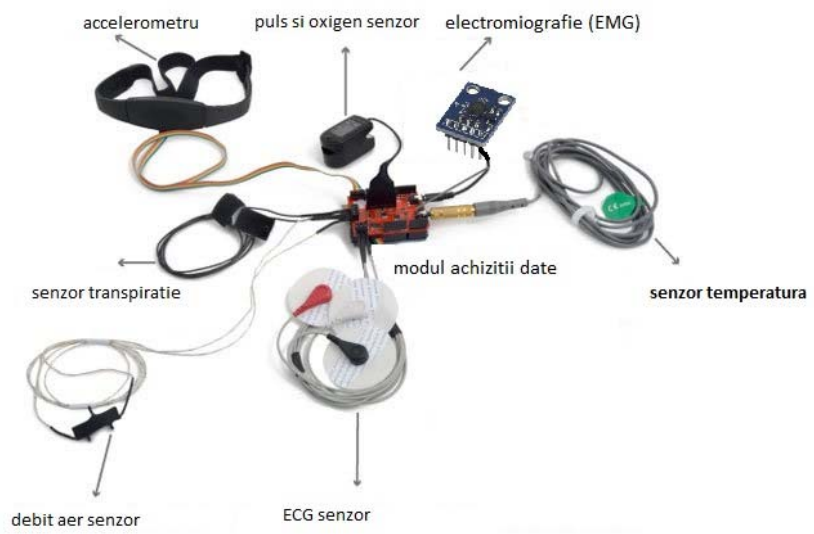

Figure 5. The sensors.

Techniques used:

- For electronic Design The Autodesk EAGLE program was used.

- Software development Prototyping ARDUINO I.D.E.

- For making Office charts.

- For data acquisition PLX-DAQ via RS232.

\subsection{The mode of operation}

The acquisition of the data transmitted by the sensors on the I ${ }^{2} \mathrm{C}$ Bus is made by Micropocesorul Atmega 328 and synchronized according to time.

They are then transmitted through serial communication through a wireless module synchronized with the ship's wireless system to the ship's terminal in the control block that is under the service officer's monitoring.

The data obtained will be stored on the terminal on the ship but will also be transmitted to a terrestrial monitoring centre via satellite.

In case of exceeding preset levels the mobile unit, fixed unit, Naval and Terrestrial Command Center emits local alarms (worker, service officer) and other people in the chain of command.

These alarms will be the sound and visual nature of the latter indicating and what monitored element triggered the alarm creation and its value. 


\section{DATA AND RESULTS}

\subsection{Description of experiments}

Three tests were performed:

In Test 1 , a short series of controlled tests aimed at testing equipment performance were carried out within the work area (engine room).

The readings of the built tools were compared to the readings of more expensive classical equipment, certified.

In Test 2, within the working area (the car room) were placed on the row different variable quantities of the elements under monitoring and data were collected from the two equipment.

In Test 3, the equipment was exposed to a number of common sources of internal emission, specific to the work area.

The Working Party (working area) has been instructed to operate normally, except that the bracelet has been attached during activities, the data obtained is centralised and synchronized with the data from the fixed unit.

\subsection{The results and graphycal interpretation}

1000 values for $\mathrm{NO}_{2}$ sensor, $\mathrm{CO}$ sensor and $\mathrm{NH}_{3}$ sensor in Excel files have been collected in current time (e.g., from H16.30 to H17.56) (Table 1) and after were designed graphycal interpretations for each sensor (Figure 6, Figure 7, Figure 8).

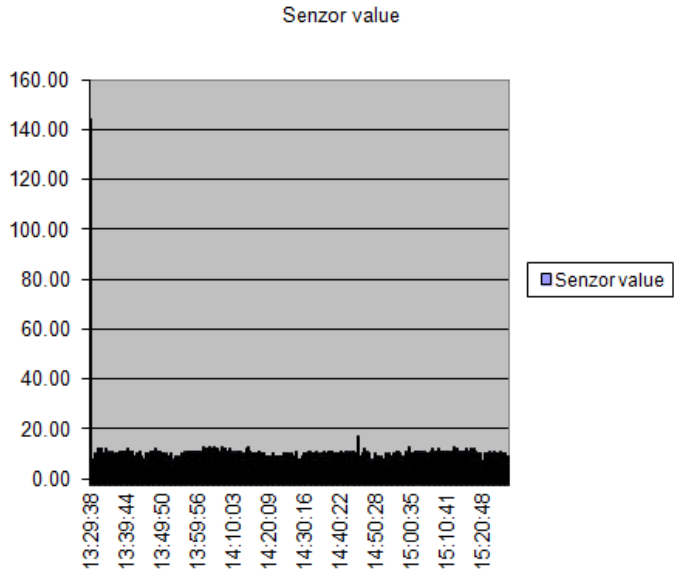

Figure 6. The sensor value.

\section{The values of sensors in current time}

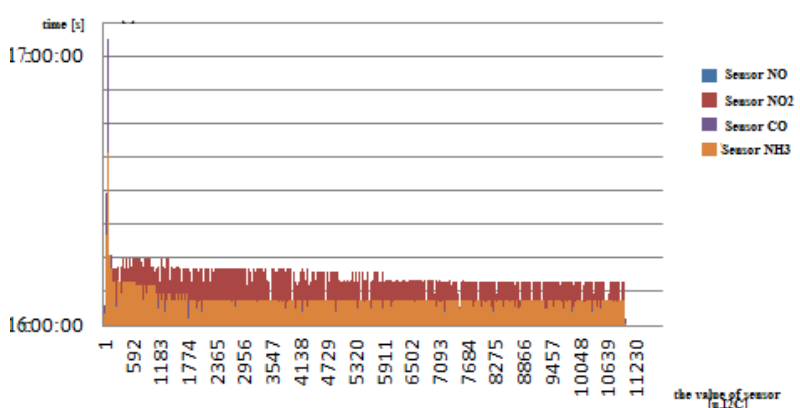

Figure 7. The values of sensors in current time.
Table 1. The real values from measurements with sensors

\begin{tabular}{|c|c|c|c|c|}
\hline \multirow{2}{*}{$\begin{array}{l}\text { Current } \\
\text { time }\end{array}$} & Senzor & Senzor & \multicolumn{2}{|c|}{ Senzor } \\
\hline & value & & value $\mathrm{CO}$ & value $\mathrm{NH} 3$ \\
\hline $16: 30: 40$ & 0.00 & 11.00 & 0.00 & \\
\hline $16: 30: 40$ & 0.00 & 0.00 & 0.00 & \\
\hline $16: 30: 40$ & 0.00 & 2.00 & 1.00 & \\
\hline $16: 30: 41$ & 0.00 & 5.00 & 4.00 & \\
\hline $16: 30: 41$ & 0.00 & 9.00 & 6.00 & \\
\hline $16: 30: 42$ & 0.00 & 11.00 & 0.00 & \\
\hline $16: 30: 42$ & 0.00 & 0.00 & 0.00 & \\
\hline $16: 30: 43$ & 0.00 & 2.00 & 2.00 & \\
\hline $16: 30: 43$ & 0.00 & 6.00 & 5.00 & \\
\hline $16: 30: 44$ & 0.00 & 9.00 & 7.00 & \\
\hline $16: 30: 44$ & 0.00 & 12.00 & 0.00 & \\
\hline $16: 30: 45$ & 0.00 & 0.00 & 0.00 & \\
\hline $16: 30: 45$ & 0.00 & 1.00 & 1.00 & \\
\hline $16: 30: 46$ & 0.00 & 6.00 & 4.00 & \\
\hline $16: 30: 46$ & 0.00 & 8.00 & 5.00 & \\
\hline $16: 30: 46$ & 0.00 & 11.00 & 0.00 & \\
\hline $16: 30: 47$ & 0.00 & 0.00 & 0.00 & \\
\hline $16: 30: 47$ & 0.00 & 0.00 & 0.00 & \\
\hline $16: 30: 48$ & 0.00 & 1.00 & 2.00 & \\
\hline $16: 30: 48$ & 0.00 & 6.00 & 4.00 & \\
\hline $16: 30: 49$ & 0.00 & 8.00 & 5.00 & \\
\hline $16: 30: 49$ & 0.00 & 11.00 & 0.00 & \\
\hline $16: 30: 50$ & 0.00 & 0.00 & 0.00 & \\
\hline $16: 30: 50$ & 0.00 & 0.00 & 0.00 & \\
\hline $16: 30: 51$ & 0.00 & 2.00 & 2.00 & \\
\hline $16: 30: 51$ & 0.00 & 6.00 & 4.00 & \\
\hline $16: 30: 51$ & 0.00 & 9.00 & 6.00 & \\
\hline $16: 30: 52$ & 0.00 & 11.00 & 0.00 & \\
\hline $16: 3: 52$ & 0.00 & 0.00 & 0.00 & \\
\hline $16: 30: 53$ & 0.00 & 0.00 & 0.00 & \\
\hline $16: 30: 53$ & 0.00 & 1.00 & 2.00 & \\
\hline $16: 30: 54$ & 0.00 & 7.00 & 54.00 & \\
\hline $16: 30: 54$ & 12.00 & 79.00 & 0.00 & \\
\hline 17:56:32 & 0.00 & 1.00 & 0.00 & \\
\hline $17: 56: 32$ & 15.00 & 1.00 & 3.00 & \\
\hline $17: 56: 33$ & 0.00 & 2.00 & 2.00 & \\
\hline $17: 56: 33$ & 1.00 & 0.00 & 5.00 & \\
\hline $17: 56: 34$ & 0.00 & 2.00 & 5.00 & \\
\hline $17: 56: 34$ & 0.00 & 0.00 & 0.00 & \\
\hline $17: 56: 35$ & 5.00 & 0.00 & 0.00 & \\
\hline $17: 56: 35$ & 6.00 & 1.00 & 8.00 & \\
\hline $17: 56: 36$ & 0.00 & 10.00 & 10.00 & \\
\hline $17: 56: 36$ & 1.00 & 0.00 & 0.00 & \\
\hline $17: 56: 36$ & 14.00 & 5.00 & 8.00 & \\
\hline $17: 56: 37$ & 0.00 & 0.00 & 0.00 & \\
\hline $17: 56: 37$ & 1.00 & 0.00 & 0.00 & \\
\hline $17: 56: 38$ & 1.00 & 0.00 & 6.00 & \\
\hline $17: 56: 38$ & 0.00 & 11.00 & 0.00 & \\
\hline $17: 56: 39$ & 15.00 & 1.00 & 0.00 & \\
\hline $17: 56: 39$ & 26.00 & 5.00 & 8.00 & \\
\hline $17: 56: 40$ & 0.00 & 3.00 & 1.00 & \\
\hline $17: 56: 40$ & 0.00 & 5.00 & 1.00 & \\
\hline $17: 56: 41$ & 0.00 & 5.00 & 0.00 & \\
\hline $17: 56: 41$ & 10.00 & 5.00 & 0.00 & \\
\hline $17: 56: 41$ & 8.00 & 0.00 & 8.00 & \\
\hline $17: 56: 42$ & 0.00 & 10.00 & 0.00 & \\
\hline $17: 56: 42$ & 6.00 & 1.00 & 15.00 & \\
\hline $17: 56: 43$ & 1.00 & 0.00 & 1.00 & \\
\hline $17: 56: 43$ & 8.00 & 1.00 & 10.00 & \\
\hline $17: 56: 44$ & 0.00 & 0.00 & 1.00 & \\
\hline $17: 56: 44$ & 0.00 & 4.00 & 1.00 & \\
\hline
\end{tabular}

The test results which are measured by 3 sensors (Table 1) in the same time are different, because the qualities of these new generation sensors are being tested and some sensors do not respond correctly to changes in the parameters in the premises. That's why three measurements are made, finally taking their average value. 


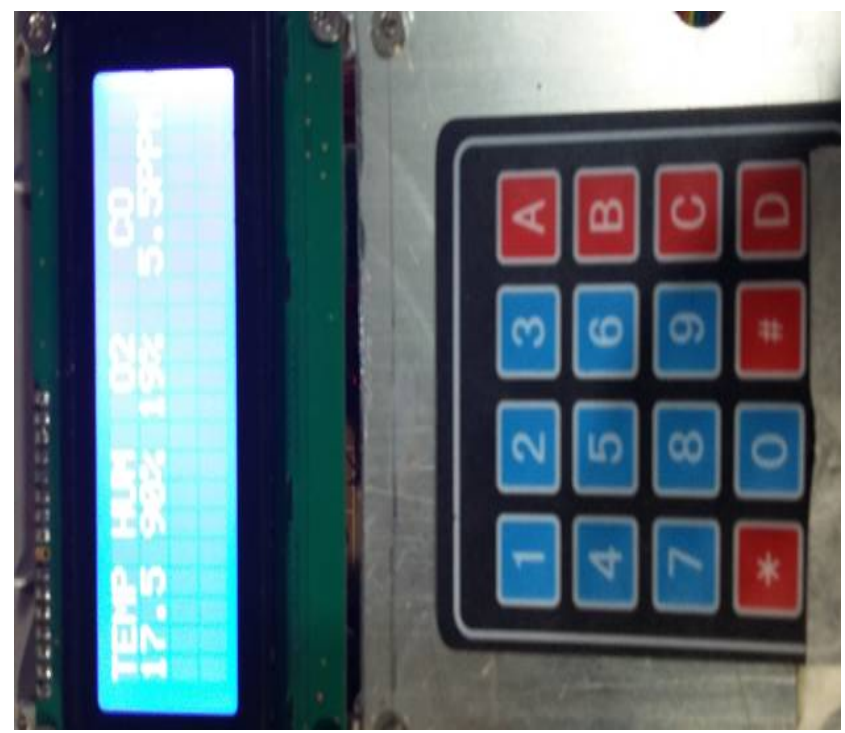

Figure 8 . The measurements for temperature, humidity and $\mathrm{CO}$ with experimental equipment.

During measurements the equipment created alert the high values in the measuring enclosure (Figure 9).

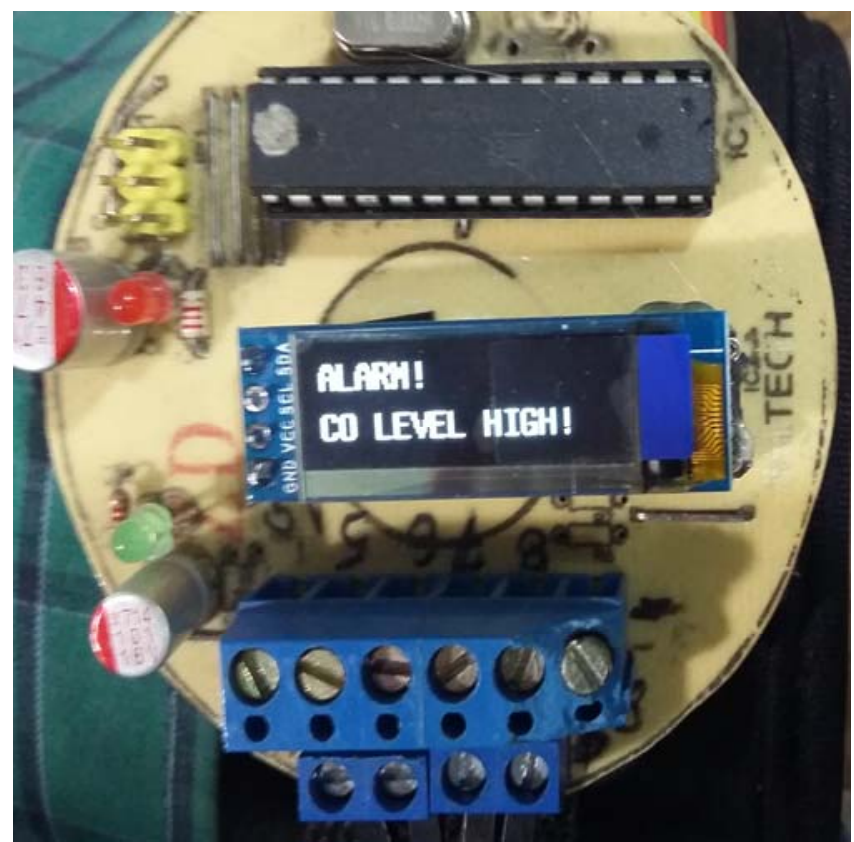

Figure 9. The alert CO level.

Reference values for air quality indicators (according to GO No. 582/2002) measured in the air for 1 hour, measured alert threshold for 3 consecutive hours:

- SO2-350 $\mu \mathrm{g} / \mathrm{m} 3$; Alert Threshold-500 $\mu \mathrm{g} / \mathrm{m}^{3}$

- $\mathrm{NO}_{2}-200 \mu \mathrm{g} / \mathrm{m}^{3} \mathrm{NO}_{2}$; Alert Threshold $-400 \mu \mathrm{g} / \mathrm{m}^{3}$

- Particulate matter (PM10)-value at $24 \mathrm{~h}-50 \mu \mathrm{g} / \mathrm{m}^{3}$ PM10; Top rating threshold-at 24 hours- $60 \%$ of daily limit value $\left(30 \mu \mathrm{g} / \mathrm{m}^{3}\right)$

- CO-The maximum daily average value of 8 hours$10 \mu \mathrm{g} / \mathrm{m}^{3}$

- Ozone-the maximum daily value of averages on 8 hours-120 $\mu \mathrm{g} / \mathrm{m}^{3}$; Alert threshold at 1 hour- $240 \mu$ $\mathrm{g} / \mathrm{m}^{3}$

The volume must be expressed under standard conditions (temperature of $293{ }^{\circ} \mathrm{K}$ and pressure of $101.3 \mathrm{kPa}$ ).
The limits applicable in ECAs (Emission Control Areas (ECAs) designated under regulation 13 of MARPOL Annex VI for SOx and particulate matter were reduced to $0.10 \%$, from 1 January 2015(www.imo.org).

Progressive reductions in NOx emissions from marine diesel engines installed on ships are also included, with a "Tier II" emission limit for engines installed on a ship constructed on or after 1 January 2011; and a more stringent "Tier III" emission limit for engines installed on a ship constructed on or after 1 January 2016 operating in ECAs. Marine diesel engines installed on a ship constructed on or after 1 January 1990 but prior to 1 January 2000 are required to comply with "Tier I" emission limits, if an approved method for that engine has been certified by an Administration (www.imo.org). These emissions can be measured with these fixed and mobile units during operational processes in ship cart. The mobile unit can adjusted for each member of crew.

The measured data were compared with the values indicated by standard certified equipment. The standard equipment for measurements in the machinery compartment is the $\mathrm{CO}_{2}, \mathrm{O}_{2}, \mathrm{NO}$ combustion gas Analyser, (Figure 10) (http://www.afriso.ro).

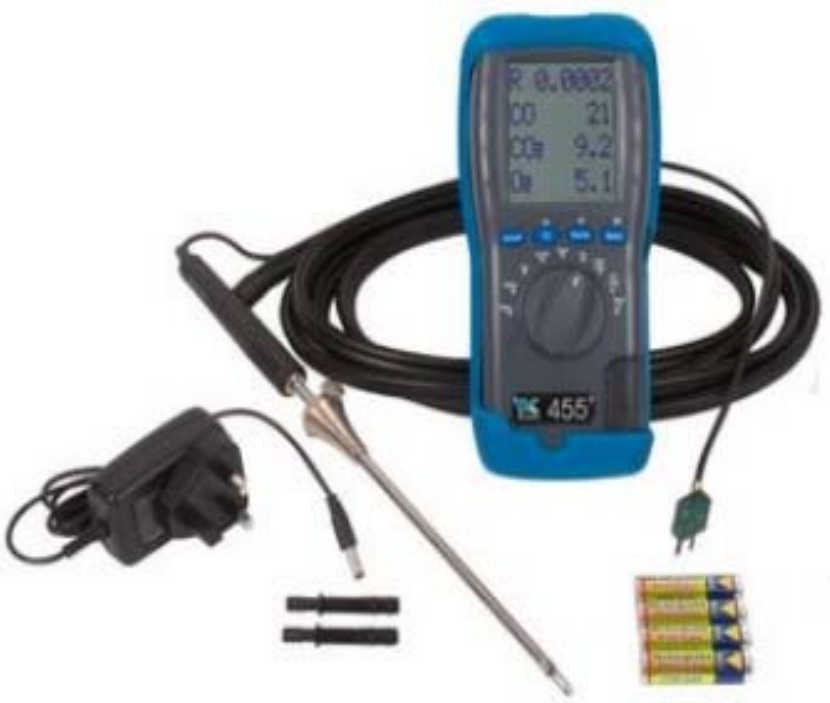

Figure 10. The combustion gas analyser.

The errors obtained are below $2 \%$.

\section{CONCLUSIONS}

Experiments have shown that the choice of sensors with $\mathrm{I}^{2} \mathrm{C}$ communication was a good, viable, achievable choice.

Sensor readings fall into the prewritten tolerances.

No need for a sensor calibration.

The constructive dimensions of the bracelet were not very small at first realization, but they can be reduced considerably in the case of industrial manufacture.

During the tests it was spotted that the data provided by the pressure sensor and temperature can 
be converted in height, indicating the position of the worker vertically in the ship.

The qualities of these new generation of sensors lead to the elaboration of new concepts (visions) of monitoring/reporting/alarm systems on board ships, eliminating errors introduced by the human factor in this chain.

The work also shows one of these new visions. The acquisition of correlation and transmission of data from the two systems designed and made, based on the new generation of sensors provides a picture of the impact of air quality on the crew working in the car room.

\section{REFERENCES}

Dumitrescu, M.V., Studies on techniques and technologies for monitoring and control of environmental factors ( Studii asupra tehnicilor si tehnologiilor de monitorizare si control a factorilor de mediu), Referat doctorat, 2018, Politehnica University, Bucuresti, Romania.

*** "Schools Indoor Pollution and Heath: Observatory Network in Europe", http://www.sinphonie.eu, 2018.

Viegi, G., \& others, Indoor air pollution and airway disease, Int.J.Tuberc Lung Disease, 2004; 8:1401

Geller, R.J., \& others, Safe and healty school environments, Pediatric Clin.J,. North America, 2007, 54:351.

*** The combustion gas analyser, http://www.afriso.ro/.

***ECAs- Emission-Control-Areas, http://www.imo.org/en/OurWork/Environment/Pollutio nPrevention/AirPollution/Pages/Emission-Control-

Areas-\%28ECAs\%29-designated-under-regulation-13-ofMARPOL-Annex-VI-\%28NOx-emissioncontrol\%29.aspx 